\title{
Laser-surface-alloyed carbon nanotubes reinforced hydroxyapatite composite coatings
}

\author{
Yao Chen, ${ }^{\text {a) }}$ Cuihua Gan, Tainua Zhang, and Gang Yu \\ The State Key Laboratory of Nonlinear Mechanics, Institute of Mechanics, Chinese Academy of Sciences, \\ Beijing 100080, People's Republic of China \\ Pucun Bai \\ Inner Mongolia University of Technology, Huhejapte 010062, People's Republic of China
}

Alexander Kaplan

Division of Manufacturing System Engineering, Lulea University of Technology, SE 97181, Lulea, Sweden

(Received 11 February 2005; accepted 18 May 2005; published online 14 June 2005)

\begin{abstract}
Carbon-nanotube (CNT)-reinforced hydroxyapatite composite coatings have been fabricated by laser surface alloying. Microstructural observation using high-resolution transmission electron microscopy showed that a large amount of CNTs remained with their original tubular morphology, even though some CNTs reacted with titanium element in the substrate during laser irradiation. Additionally, measurements on the elastic modulus and hardness of the composite coatings indicated that the mechanical properties were affected by the amount of CNTs in the starting precursor materials. Therefore, CNT-reinforced hydroxyapatite composite is a promising coating material for high-load-bearing metal implants. (C) 2005 American Institute of Physics.
\end{abstract}

[DOI: 10.1063/1.1951054]

Hydroxyapatite ( $\left.\mathrm{HA}: \mathrm{Ca}_{10}\left(\mathrm{PO}_{4}\right)_{6}(\mathrm{OH})_{2}\right)$ is widely preferred as a biomaterial that has attracted great attention mainly because it has a crystallographic structure similar to apatite crystallites in living bone tissues, ${ }^{1-3}$ and therefore it has osteoconductive and bioactive properties that promote rapid bone formation and strong biological fixation to bony tissues. ${ }^{4}$ Furthermore, the special structural characteristics of single crystal HA, namely, dipolar-type defect chemistry, render it extremely interesting dielectrics of a new functional material. ${ }^{5}$ Unfortunately, its usage under high load-bearing conditions is restricted due to its brittle nature and poor strength. ${ }^{6}$ Hence, there is a need for increasing the mechanical properties of these materials suitable for clinical applications. The problem can be solved through either fabricating fibrous HA-reinforced poly (ethylene oxide) composites ${ }^{7}$ and HA whiskers-reinforced high-density polyethylene composites, ${ }^{8}$ exhibiting improved mechanical properties, or applying HA as a covering material for titanium or other metal used in implants, in which the biocompatibility is assured by HA while the mechanical aspects are provided by the metal-matrix material. ${ }^{9}$ Considerable efforts have been made in resent years to develop HA coatings ${ }^{10-13}$ or HAbased composite coatings that are reinforced with bionert ceramics such as zirconia $\left(\mathrm{ZrO}_{2}\right)^{14}$ by a plasma spraying technique. Although many experimental studies have illustrated that plasma sprayed hydroxyapatite coatings on a metal substrate can induce a direct chemical bond with bone tissues and hence achieve biological fixation of the implants, the bonding strength of the HA /metal interface has been a important point of potential weakness in prosthesis. ${ }^{15}$ As is known, carbon nanotubes (CNTs) possess excellent mechanical properties and chemical stability which result from their cylindrical graphitic structure. It is worth noting that carbon

\footnotetext{
a) Author to whom correspondence should be addressed; electronic mail:
} chenyao27@163.com is one of known fundamental elements in the development of life on the planet Earth. ${ }^{16}$ Therefore, hydroxyapatite coating reinforced with CNTs might have excellent properties including high strength and excellent bioactivity. Additionally, metallurgical bonding of coating/substrate can be obtained by laser surface processing, improving effectively the bond strength of HA/metal. In this letter, the laser surface alloyed CNTs reinforced HA bioactive composite coatings are reported, in which the CNTs with their original tubular morphology dispersed in the HA matrix, and the properties of the bioactive coating have been improved.

Commercially hydroxyapatite powder with an average particle size ranging from $30-50 \mu \mathrm{m}$ and the commercially multiwalled CNTs with a diameter from $20-40 \mathrm{~nm}$ and the length from 5-15 $\mu \mathrm{m}$ were selected as starting precursor materials for fabricating CNTs reinforced hydroxyapatite composite coatings by a laser surface alloying technique. The CNT powder was cleaned in acetone and dehydrated at $473 \mathrm{~K}$ before mixing with hydroxyapatite powder. The powder mixtures were mechanically ball milled together in four different weight proportions, namely $0 \%, 5 \%, 10 \%$ and $20 \%$ CNTs. The substrate used for the coatings was of Ti-6Al-4V with a dimension size of $60 \times 30 \times 5 \mathrm{~mm}$. Prior to laser surface alloyed composite coatings, the substrates were preheated to reduce the residual thermal stress. The experiments of laser surface alloying were carried out using a HL2006D $\mathrm{Nd}$ :YAG laser, and the laser processing parameters were selected as: Laser outpower $400 \mathrm{~W}$, beam diameter $4.0 \mathrm{~mm}$ and the beam scanning speed $4 \mathrm{~mm} / \mathrm{s}$. Microstructure was characterized using high-resolution transmission electron microscopy (HRTEM) in a JEM-2010 operating at $200 \mathrm{kV}$. Phase constituents of composite coatings were analyzed by x-ray diffraction (XRD) using a Rigaku D/max 2200 diffractometer with $\mathrm{Cu} K_{\alpha}$ radiation operated at a voltage of $40 \mathrm{kV}$, a current of $40 \mathrm{~mA}$ and a scanning rate of $5^{\circ} / \mathrm{min}$. Nanoindentation tests were conducted using a MTS Nano Indenter ${ }^{\circledR}$ XP with a Berkvich diamond tip. Hardness and elastic modu- 


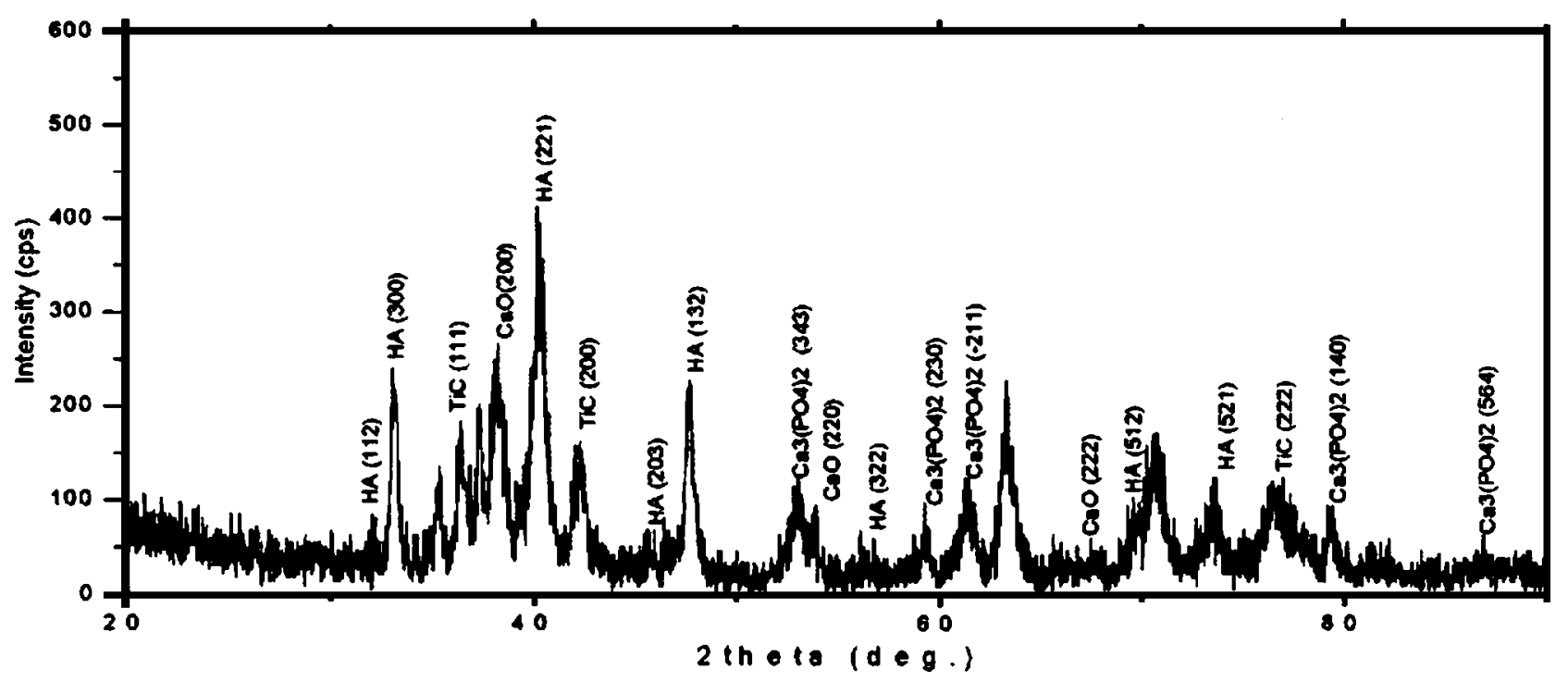

FIG. 1. XRD patterns of the laser surface alloyed coating with a powder mixture of HA-10\%CNT (wt \%).

lus of the coating were measured as a function of indentation depth using a continuous stiffness measurement Method.

Figure 1 shows XRD results of the laser surface alloyed coating with a powder mixture of HA-10\% CNTs (wt \%), which can be clearly seen that the phase constituents of the coating are the $\mathrm{HA}, \mathrm{CaO}, \mathrm{TCP}$, and $\mathrm{TiC}$. The results indicates that the CNTs have reacted partially with Ti, from Ti-6Al-4V substrate, to form $\mathrm{TiC}$, and HA has partially decompose into $\mathrm{CaO}$ and TCP. It is well known that the titanium element has a much larger negative heat of formation $(184.0 \mathrm{~J} / \mathrm{mol})$ with carbon than that of other elements in the laser-generated pool, suggesting that $\mathrm{Ti}$ and $\mathrm{C}$ have the largest driving force to form $\mathrm{TiC}$. Therefore, the reaction of $\mathrm{Ti}$ with $\mathrm{C}$ is favored during the laser surface alloying. Also, the temperature of the laser-generated pool is higher than the melting point of HA $\left(1450{ }^{\circ} \mathrm{C}\right)$, leading to the decomposition of $\mathrm{HA}$ to form $\alpha$-TCP and TTCP. Being an unstable phase at room temperature, $\alpha$-TCP naturally transforms to $\beta$-TCP (a stable phase at room temperature) at about $1100{ }^{\circ} \mathrm{C} .{ }^{17}$ As for the TTCP phase, it would further decompose to form $\mathrm{HA}$ and $\mathrm{CaO} .^{18}$

Transmission electron microscopy (TEM) and HRTEM observations are conducted to confirm the existence of CNTs in the laser surface alloyed coating, and the images are shown in Fig. 2. Figure 2(a) shows a typical tubular morphology of as-prepared CNTs. Figure 2(b) shows the typical morphology of residual CNTs in the coating. It is obvious that some CNTs with their originally tubular structure can be observed after laser surface alloying. Furthermore, the selected area diffraction pattern in the matrix of the coating shows that the matrix is hydroxyapatite [Fig. 2(c)]. HRTEM observation is employed to investigate further the detailed structure of CNTs in the coating, as shown in Fig. 2(d). It is clearly seen that CNTs still keep their cylindrical graphitic structure due to the high thermal stability and the high chemical stability of the CNTs. ${ }^{19,20}$ According to the above results, the CNTs have been successfully introduced into the HA matrix using laser surface alloying.

In the present work, nanoindentation was used to study the variation of the physical properties of laser surface alloyed coatings with different CNT content. As shown in Fig. 3 , It displays that the load increases with increasing content of carbon nanotube in the powder mixtures, indicating that Downloaded 14 Jun 2005 to 159.226.231.143. Redistribution subject the higher the content of carbon nanotube, the higher the hardness and the elastic modulus. After removal of the indenter tip, the plastic deformation of CNT-free coating is about $1480 \mathrm{~nm}$, while $1290 \mathrm{~nm}$ for the HA-20\%CNTs coating. This means the CNT-free hydroxyapatite coating undergoes a larger plastic deformation during nanoindentation experiments. The average hardness and modulus for these coating are indicated in Table I. It shows that the hardness of these coatings increases with increasing of CNT content. It is well known that the CNT is one of the stiffest structures ever made $^{21}$ and TiC has higher hardness. Therefore, the residual CNTs and the in situ formation of $\mathrm{TiC}$ in the hydroxyapatite matrix, especially the residual CNTs, have an effective strengthening role. It has been reported that the value of the
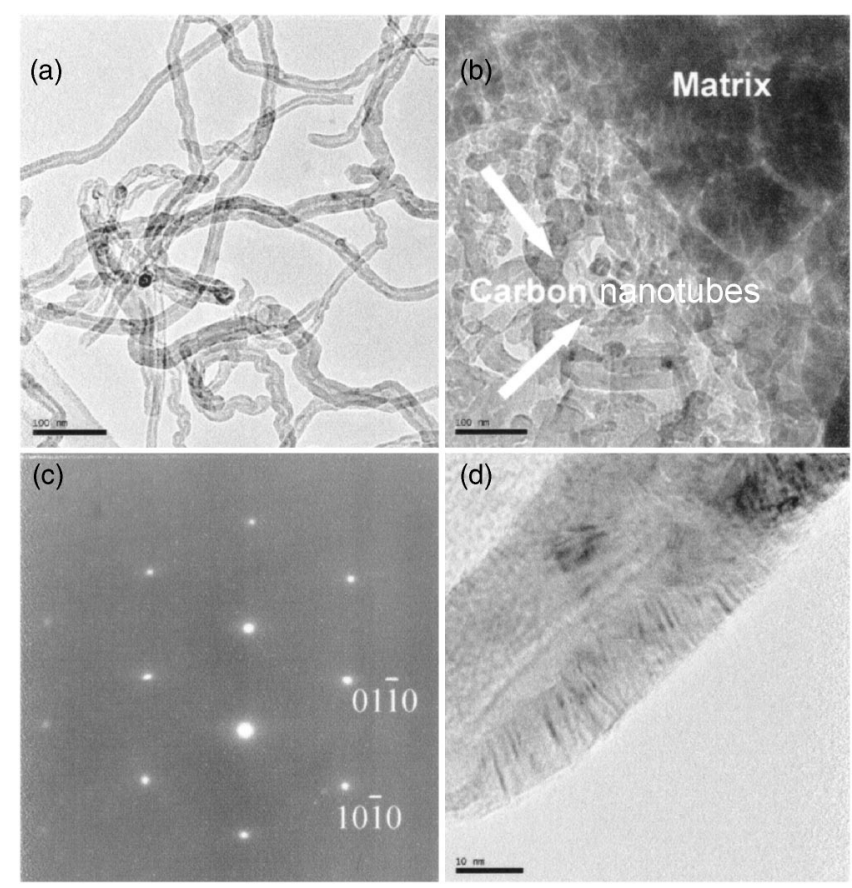

FIG. 2. TEM image showing the typical morphology of as-prepared CNTs (a), residual CNTs in laser surface alloyed coating (b), the selected area diffraction pattern of HA in the direction of [0001] (c), and HRTEM image of the CNT distributed in the coating (d).
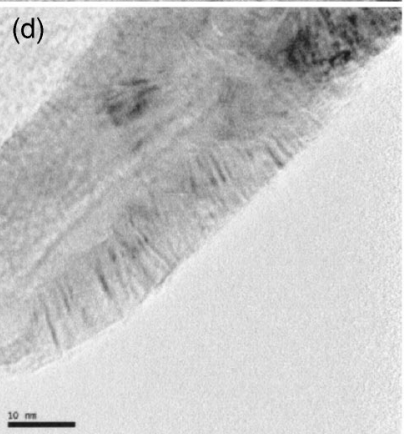


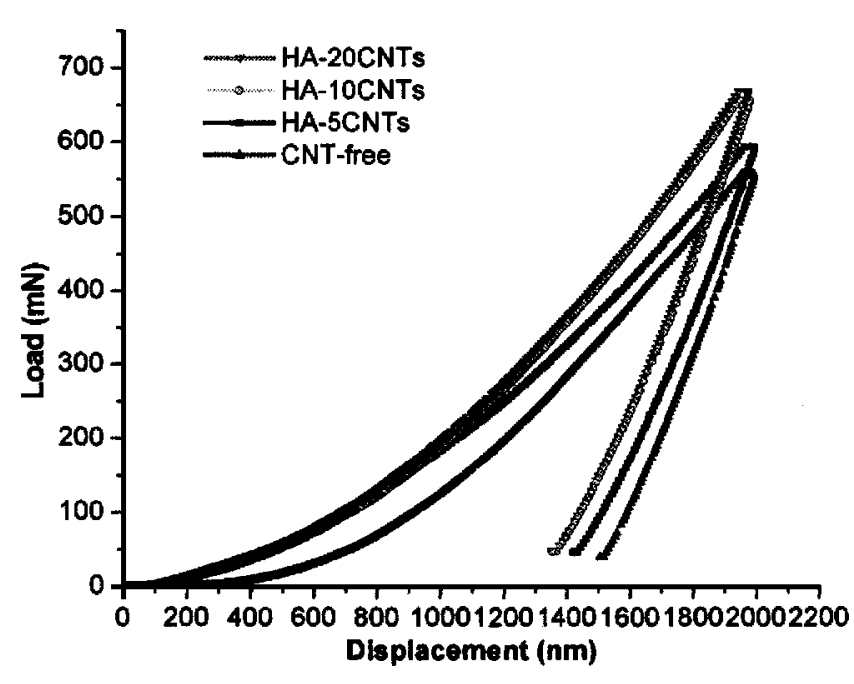

FIG. 3. Typical load-displacement curves of laser surface alloyed coating with different CNT content.

elastic modulus of CNT is as high as approximately 1.8 $\mathrm{TPa},{ }^{21}$ which is much larger than that of hydroxyapatite. Generally, the addition of small content residual CNTs can cause the notable increase in the elastic modulus of these CNTs reinforced hydroxyapatite coatings according to the simple rule of mixtures. The relative changes in hardness and modulus, $\left(Y-Y_{H}\right) / Y_{H}\left(Y_{H}\right.$ is the parameters of the CNT-free coating, $Y$ are the parameters of the CNTs reinforced coatings) are shown in Fig. 4. It is clearly seen that the addition of CNTs does not have a strong effect on the value of modulus of these coatings. The reason for this phenomenon might be that the multiwalled CNT usually has structural defects, which can result in the notable decrease of the value of the modulus. ${ }^{22}$ It is worth noting that the higher the value of the modulus of the biomaterial coating, the stronger the mismatch between coating and living bone tissues, due to the small valve of the modulus of the bone tissues (20-30 GPa). Compared with the CNT-free hydroxyapatite coating, the remarkable increase in the hardness and slight increase in the modulus of the CNT reinforced hydroxyapatite coating has a potential contribution toward improving the bone repair.

In conclusion, CNT reinforced hydroxyapatite coating was fabricated using laser surface alloying. The composite coating consists of the hyaroxyapatite matrix, $\mathrm{TiC}, \mathrm{CaO}$, TCP, and residual CNTs that still keep their tubular structure. The addition of CNTs results in the remarkable increase in both hardness and slight increase in modulus, which suggests that CNT reinforced hydroxyapatite coating is a promise for

TABLE I. Values of hardness and modulus of different laser surface alloyed coatings.

\begin{tabular}{lcccc}
\hline \hline & $\begin{array}{c}\text { CNT-free } \\
\text { coating }\end{array}$ & $\begin{array}{c}\text { HA-5\%CNT } \\
\text { coating }\end{array}$ & $\begin{array}{c}\text { HA-10\%CNT } \\
\text { coating }\end{array}$ & $\begin{array}{c}\text { HA-20\%CNT } \\
\text { coating }\end{array}$ \\
\hline$H(\mathrm{GPa})$ & 9.047 & 9.743 & 11.026 & 12.811 \\
$E(\mathrm{GPa})$ & 149.435 & 152.186 & 164.265 & 180.604 \\
\hline \hline
\end{tabular}

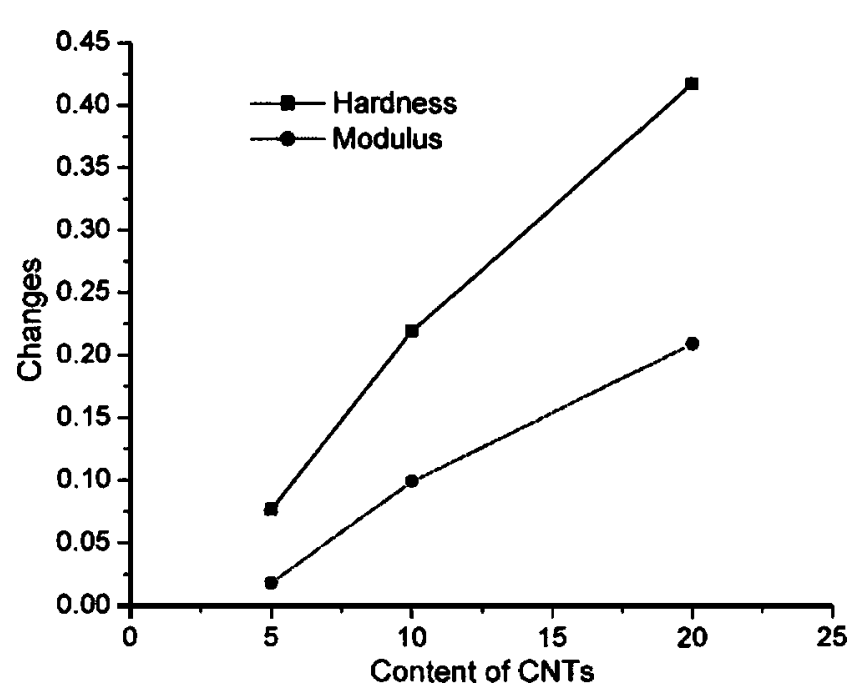

FIG. 4. Relative changes in hardness and modulus as a function of content of CNTs.

improving the long-term stability of the bioactive coating under high load-bearing conditions.

The authors are grateful to the financial support of the Natural Science Foundation of China (Grant Nos. 50471088 and 10372103) and China Postdoctoral Science Foundation (Grant No. 2004035073).

${ }^{1}$ W. Suchanek and M. Yoshimura, J. Mater. Res. 13, 94 (1998).

${ }^{2}$ G. Willmann, Adv. Eng. Mater. 1, 95 (1999).

${ }^{3}$ R. J. B. Sakkers, R. A. J. Dalmeyer, R. Brand, P. M. Rozing, and C. A. van Blitterswijk, J. Biomed. Mater. Res. 36, 265 (1997).

${ }^{4}$ K. A. Khor and P. Cheang, Proceedings of the Seventh National Thermal Spray Conference, Boston, 20-24 June 1994, p. 147.

${ }^{5}$ I. M. Kalogeras, A. Vassilikou-Dova, and A. Katerinopoulou, J. Appl. Phys. 92, 406 (2002).

${ }^{6}$ L. L. Hench, J. Am. Ceram. Soc. 81, 1705 (1998).

${ }^{7}$ R. Banat and T. Tincer, J. Appl. Polym. Sci. 90, 488 (2003).

${ }^{8}$ R. K. Roader, M. M. Sproul, and C. H. Turner, J. Biomed. Mater. Res., A67, 801 (2003).

${ }^{9}$ V. V. Silva and R. Z. Domingues, J. Mater. Sci. 8, 907 (1997).

${ }^{10}$ K. de Groot, R. Geesink, C. P. A. T. Klein, and P. Serekian, J. Biomed. Mater. Res. 21, 1375 (1987).

${ }^{11}$ C. P. A. T. Klein, P. Patka, H. B. M. van der Lubbe, J. G. C. Wolke, and K. de. Groot, J. Biomed. Mater. Res. 25, 53 (1991).

${ }^{12}$ Y. W. Gu, K. A. Khor, D. Pan, and P. Cheang, Biomaterials 25, 3177 (2004).

${ }^{13}$ K. A. Khor, Y. W. Gu, C. H. Quek, and P. Cheang, Surf. Coat. Technol. 168, 195 (2003).

${ }^{14}$ V. J. P. Lim, K. A. Khor, L. Fu, and P. Cheang, J. Mater. Process. Technol. 89, 491 (1999).

${ }^{15}$ K. A. Khor, L. Fu, V. J. P. Lim, and P. Cheang, Mater. Sci. Eng., A 160, 276 (2000).

${ }^{16}$ H. M. Cheng, Carbon Nanotubes Synthesis, Microstructure, Properties and Applications (Chemistry, Beijing, 2002), p. 4.

${ }^{17}$ H. X. Ji and P. M. Marquis, Biomaterials 14, 64 (1993).

${ }^{18}$ B. Lorcardi, U. E. Pazzaglia, C. Gabbi, and B. Profilo, Biomaterials 14, 437 (1993).

${ }^{19}$ S. Iijima and T. Ichihashi, Nature (London) 363, 603 (1993).

${ }^{20}$ T. W. Ebbesen and P. M. Ajayan, Nature (London) 358, 220 (1992).

${ }^{21}$ M. M. J. Treacy, T. W. Ebbesen, and J. M. Gibson, Nature (London) 381, 678 (1996).

${ }^{22}$ R. P. Gao, Z. L. Wang, Z. G. Wang, W. A. Heer, L. M. Dai, and M. Gao, Phys. Rev. Lett. 85, 622 (2000). 